\title{
LUCC Temporal Features and Driving Forces of the Wohu Basin
}

\author{
Ke Kong ${ }^{1, a^{*}}$, Xin Cong $^{1, b}$ and Zhenghe $\mathrm{Xu}^{1, \mathrm{c}}$ \\ ${ }^{1}$ University of Jinan, Jinan, Shandong Province, China \\ akoker@sohu.com, bcongxin1994@126.com, xu4045@126.com
}

Keywords: Land use and cover change; Driving forces; Temporal features; Primary component analysis; Wohu basin

\begin{abstract}
The land use and cover change (LUCC) is more and more intensive in China for the rapid urbanization in recent years. Five remote sense images in 1988, 1996, 2002, 2009 and 2014 are used to analyze the temporal LUCC features in the Wohu basin in Jina city. Through calculating the special variance trend degree, it is obtained that residential area, water and road almost kept increasing in the past three decades while the grassland, farmland and forest kept decreasing; Calculation of integrated variance trend degree shows that the most intensive LUCC happened from 1988 to 1996 and the LUCC became weaker from 2009 to 2014. Twelve LUCC influence factor are select and the method of primary component analysis is carried out and give the results that the population and economy factors are the most important driving forces of LUCC in the basin. This study can provide reference for land use planning and sustainable development in the Wohu basin.
\end{abstract}

\section{Introduction}

Following the rapid development of population and economy, the cities in China expand gradually and the exploit and utility of land become intensive, so that the land use and cover change (LUCC) is more and more obvious. In many districts of China, tissues about LUCC have been studied [1,2]. For any basin, the LUCC effects its sustainable development, because in the process of LUCC not only the land resources change but the hydrological conditions of basin are changed also, which will influence the hydrology procedure. The total amount of water resources available for use may vary and the flood peak will shift. Land and water changing together will no doubt influence the basin both in environment and in society. To study LUCC, the remote sense images form Landsat and SPOT are necessary [3,4]. This study use a series of remote sense images of the Wohu basin, which is the ground water resources location of the Jinan city, the famous spring water city in China, to analyze the LUCC of this area. During the past three decades the local economy and population of the basin developed rapidly, so the conflict of local economy development and environment protection becomes intensive. For this reason, this analysis is hoped to provide some useful advices for the rational planning of local industries assignment and the rational use of land, water and other resources, therefore to promote the coordinate development of the local economy and environment.

\section{Study Area and Data}

The Wohu basin locates in the north of the Tai Mountain and in the south of Jinan city. It includes three sub-basins: Jinyangchuan, Jinxiuchuan and Jinyunchuan. It has low hill topography with higher in south and lower in north. Its climate belongs to continent monsoon type with little rainfall in March to May and a lot of rainfall in hot summer. The basin covers 78 villages in the towns of Xiying, Zhonggong and Jinxiuchuan; it is the east bound of the groundwater source location of the Jinan city and its most area locate in this source location [5]. In tradition, agriculture is most important and there is little other industry in the basin, but in the recent years, the industry and tourism develop very fast, which promote the local population and economy and at same time leads to an intense land use-cover change. To analyze the LUCC of basin in the past three decades, this study select five remote sense images in the year of 1988, 1996, 2002, 2009 and 2014 to construct a series of LUCC maps. These remote sense 
images are obtained from TM and SPOT, pre-disposed by ENVI, reclassified by the method of maximum likelihood, and calibrated by the data from Google map service.

The land use-cover type is divided into 8 kinds: water, farmland, low density residential area, high density residential area, deciduous forest, evergreen forest, grassland and road. Using AicGis9, we count the areas of such eight kinds of land use-cover in different years, as shown in Table 1.

Table 1 Areas of different kinds of land use-cover type in different year $\left[\mathrm{km}^{2}\right]$

\begin{tabular}{cccccc}
\hline $\begin{array}{c}\text { Land use-cover } \\
\text { type }\end{array}$ & 1988 & 1996 & 2002 & 2009 & 2014 \\
\hline Water & 5.81 & 8.37 & 8.21 & 8.43 & 8.69 \\
High density & 3.36 & 3.48 & 3.59 & 3.63 & 3.63 \\
residential area & & & & & \\
Low density & 11.42 & 13.63 & 16.07 & 18.33 & 19.56 \\
residential area & 76.85 & 74.37 & 72.01 & 71.54 & 71.01 \\
Grassland & 128.6 & 127.45 & 126.67 & 125.34 & 124.74 \\
Farmland & 137.67 & 137.3 & 137.19 & 137.14 & 137.06 \\
Deciduous Forest & 258.12 & 255.63 & 254.58 & 253.65 & 253.25 \\
Evergreen forest & 8.06 & 9.72 & 11.59 & 11.85 & 11.97 \\
Road & & & & & \\
\hline
\end{tabular}

Although the areas of different kinds of land use-cover are all changed during the past three decades, but the sequence of area of different land use-cover from the maximum to the minimum is kept invariant, i.e. evergreen forest, deciduous forest, farmland, grassland, low density residential area, high density residential area, water, and road. The three prominent types are evergreen forest, deciduous forest and farmland, whose total area account for more than $80 \%$ of the whole Wohu basin.

\section{LUCC Temporal Features of the Basin}

From Table 1, it is can see that water, high density residential area, low density residential area and road develop more and more rapidly from 1988 to 2014. Grassland, farmland and forest reduced continuously at the same time. For more details two indexes for LUCC temporal feature are often used, i.e. special variance trend degree and integrated variance trend degree of LUCC [6,7]. Through these two indexes, not only the past and current LUCC properties can be analyzed, but the future can be forecasted under the assumption that the relevance between LUCC and time is linear.

Special Variance Trend Degree of LUCC. Special trend degree is used to describe the feature of a single type of LUCC. The method of calculating this degree is shown as Eq.1.

$$
R_{i T}=\frac{U_{i b}-U_{i a}}{U_{i a}} \times \frac{1}{T} \times 100 \%
$$

where $R_{i T}$ denotes trend degree of the $i$ th kind of land use-cover type during time $T ; T$ denotes time span, in this study it is year; $U_{i a}$ and $U_{i b}$ respectively denote the initial area and the end area of the $i$ th kind of land use-cover type .

Merging low density residential area and high density residential area to residential area, the seven kind of single variance trend degree can be calculated, the data are shown in Table 2.

From the calculation results, it is obvious that residential area and road keep increasing in every period of the past three decades especially from 1988 to1996 while the grassland and farmland and forest all keep decreasing. The development of residential area and road are the result of urbanization which invaded and occupied the grass, farmland and forest. The area of water also increased continually except a little decrease from 1996 to 2002 , which is caused by the building of dams to meet with the demand of local water resources. 
Table 2 Special varaiation trend degree of LUCC

\begin{tabular}{ccccc}
\hline $\begin{array}{c}\text { Land use-cover } \\
\text { type }\end{array}$ & $1988-1996$ & $1996-2002$ & $2002-2009$ & $2009-2014$ \\
\hline Water & $5.51 \%$ & $-0.32 \%$ & $0.38 \%$ & $0.62 \%$ \\
Residential area & $1.97 \%$ & $2.48 \%$ & $1.67 \%$ & $1.12 \%$ \\
Grassland & $-0.40 \%$ & $-0.53 \%$ & $-0.09 \%$ & $-0.15 \%$ \\
Farmland & $-0.11 \%$ & $-0.10 \%$ & $-0.15 \%$ & $-0.10 \%$ \\
Decidous forest & $-0.03 \%$ & $-0.01 \%$ & $-0.01 \%$ & $-0.01 \%$ \\
Evergreen forest & $-0.12 \%$ & $-0.07 \%$ & $-0.05 \%$ & $-0.03 \%$ \\
$\quad$ road & $2.57 \%$ & $3.21 \%$ & $0.32 \%$ & $0.20 \%$ \\
\hline
\end{tabular}

Integrated Variance Trend Degree of LUCC. Intergrated variance trend degree is used to describe the variance features of comprehensive land use-cover types. The method of calculating it is shown as Eq.2.

$$
L C=\left[\frac{\sum_{i=1}^{n} \nabla L_{i-j}}{2 \sum_{i=1}^{n} L U_{i}}\right] \times \frac{1}{T} \times 100 \%
$$

where $L C$ denotes the comprehensive trend degree in the basin; $L U_{\mathrm{i}}$ denotes the area of the $i$ th type of land use-cover in the initial time; $\nabla L_{i-j}$ denotes the absolute value of the varied area from the $i$ th type to the jth type; $T$ denotes time span, i.e. a year.

Through calculation we can obtain that the most intensive variation of land use-cover happened from the year 1988 to 1996 in which the integrated degree is $0.20 \%$, and weaker variation happened from the year 2009 to 2014 in which the integrated degree is $0.05 \%$. This indicates that the LUCC in the basin is becoming weaker perhaps because many environment protection measures have been carried out during the recent years for the human's recognition of the significance of the basin environment.

\section{LUCC Driving Forces Analysis}

LUCC driving forces refer to those factors which influence the change of the property of land use and the shift from one type of land use-cover to another. When the LUCC is intensive because of urbanization, the analysis of LUCC driving forces can help to give decision makers useful implication for urban-rural coordinate development [8]. The procedure of land use-cover change is complex and there are many kind of driving factors such as technology, politics, nature and economy, in addition, those factors all include many aspects, for example, the technology agricultural production methods, infrastructure systems, as well as embedded knowledge systems can all be ascribed to technology [9]. To study the LUCC driving problem of the Wohu basin, we gathered the data from the year of 2002 to 2009 and selected twelve indexes including population(X1), population natural growth rate(X2), local general net production(X3), industry production $(\mathrm{X} 4)$, agriculture production(X5), tertiary industry production(X6), local financial income(X7), local financial outcome(X8), per capital expenditure of household(X9), per capital net income of residents(X10), effective irrigation area(X11) and total fixed assets investment(X12).

In order to quantify the attributes to LUCC making by these driving indexes, primary component analysis (PCA) method is used. This method calculates eigenvalues and the corresponding variance contribution ratio of the matrix formed by indexes; then selects primary components through variance contribution rate and cumulative variance contribution rate [10]. Because the dimensions and orders of magnitude are difference, the data must be standardized using Eq.3. 


$$
P_{m j}=\frac{X_{m j}-X_{j}}{\sigma_{j}}
$$

where $P m_{j}$ denotes the standard value; $X_{m j}$ denotes original index value; $X_{j}$ denotes mathematic average value of $\mathrm{j}$ indexes; $\sigma_{j}$ denotes sample standard deviation.

Using SPSS statistics, we can obtain the PCA results shown as Table 3 and Table 4.

Table 3 Eigenvalues and variance contribution rates

\begin{tabular}{cccc}
\hline Component & Eigenvalues & \% of Variance & Cumulative \% \\
\hline 1 & 9.479 & 78.988 & 78.988 \\
2 & 1.198 & 9.983 & 88.971 \\
3 & 0.681 & 5.672 & 94.643 \\
4 & 0.324 & 2.696 & 97.340 \\
5 & 0.258 & 2.151 & 99.491 \\
6 & 0.053 & 0.441 & 99.932 \\
7 & 0.006 & 0.046 & 99.978 \\
8 & 0.002 & 0.015 & 99.993 \\
9 & 0.001 & 0.005 & 99.998 \\
10 & 0.000 & 0.001 & 100.000 \\
11 & $4.852 \mathrm{E}-05$ & 0.000 & 100.000 \\
12 & $3.589 \mathrm{E}-06$ & $2.991 \mathrm{E}-05$ & 100.000 \\
\hline
\end{tabular}

Table 4 Principal component load

\begin{tabular}{|c|c|c|}
\hline & Componet 1 & Componet 2 \\
\hline $\mathrm{X} 1$ & 0.815 & 0.383 \\
\hline $\mathrm{X} 2$ & 0.008 & 0.960 \\
\hline $\mathrm{X} 3$ & 0.981 & -0.035 \\
\hline $\mathrm{X} 4$ & 0.973 & -0.034 \\
\hline $\mathrm{X} 5$ & 0.931 & 0.048 \\
\hline $\mathrm{X} 6$ & 0.971 & -0.117 \\
\hline $\mathrm{X} 7$ & 0.928 & -0.182 \\
\hline $\mathrm{X} 8$ & 0.971 & -0.019 \\
\hline $\mathrm{X} 9$ & 0.974 & -0.078 \\
\hline $\mathrm{X} 10$ & 0.978 & -0.020 \\
\hline $\mathrm{X} 11$ & -.726 & 0.150 \\
\hline $\mathrm{X} 12$ & 0.927 & 0.222 \\
\hline
\end{tabular}

The cumulative variance contribution rate of the first primary component is $78.988 \%$, and that of the first two primary components is $88.971 \%$, more than $80 \%$, so that these two components contain $88.97 \%$ information of the twelve driving forces, and they can be used to represent them. From the point of the first primary component, population(X1), all the other components except for population nature growth rate(X2) and effective irrigation area(X11) have high loads more than 0.9 ; obviously they are all economy factors. From the point of the second primary component, population natural growth rate(X2), only population(X1) and total fixed assets investment(X12) have relative importance loads to it except for itself. So it is can be concluded that population and economy are most important factors that influence the land use-cover change in the Wohu basin. 


\section{Conclusion}

The Land use and cover change (LUCC) is the result of the development of society and economy in basin and in turn influence the basin's development. This paper uses a series remote sense images and social-economic data from 1988 to 2014 to analyze the temporal LUCC features and driving forces in the Wohu basin. Software such as ENVI, ArcGis and SPASS are used as necessary tools. Special and integrated variance trend degrees are calculate and the main results include that water, residential area and road almost kept increasing in the past three decades while the grassland, farmland and forest kept decreasing, and the LUCC from 1988 to 1996 is more intensive than from 2009 to 2014. Primary component analysis is carried out and implies that the most important driving forces of LUCC in the basin are population factors and economy factors. This study can give managers useful information for environment and economy planning.

\section{Acknowledgements}

This paper is supported by Shandong nature science fund (ZR2012DL08) and Shandong major water resources science research and technology promotion project (SDSLKY201314, SDSLKY201308, SDSLKY201410).

\section{References}

[1] W.H. Yu, S.Y. Zang and C. S.Wu: Analyzing and modeling land use land cover change (LUCC) in the Daqing City, China. Applied Geography, Vol.31 (2011), p.600.

[2] Q.D.Fan and S.Y. Ding: Landscape pattern changes at a county scale: A case study in Fengqiu, Henan Province, China from 1990 to 2013. Catena, Vol.137 (2016), p. 152.

[3] R. Pelorosso, A.Leone and L. Boccia: Land cover and land use change in the Italian central Apennines: A comparison of assessment methods. Applied Geography, Vol. 29 (2009), p.35.

[4] D.s Ruelland, F. Levavasseur and A. Tribotte: Patterns and dynamics of land-cover changes since the 1960s over three experimental areas in Mali. International Journal of Applied Earth Observation and Geoinformation, Vol.12s (2010), p.s11.

[5] L.L. Guo and Q. Li: Current situation and advices for the construction of water and soil protection in the south mountain area in Jinan. Shandong Water Resources,(2013) No.11,p.8(In Chinese).

[6] H.Y.Zhu and X.B.Li. Discussion on the index method of regional land use change. Acta Geogbaphica Sinica, Vol.58 (2003) No.5, p.643 (In Chinese).

[7] S.Y.Wang, J.Y.Liu and Z.X.Zhang: Analysis on Spatial-temporal Features of Land Use in China. Acta Geogbaphica Sinica, Vol.56 (2001) No.6, p.631 (In Chinese).

[8] Y.L. Liu, T. Luo and Z.Q. Liu: A comparative analysis of urban and rural construction land use change and driving forces: Implications for urban-rural coordination development in Wuhan, Central China. Habitat International, Vol.47 (2015), p.113.

[9] F. Hasselmanna, E. Csaplovicsb and I. Falconerc: Technological driving forces of LUCC: Conceptualization, quantification, and the example of urban power distribution networks. Land Use Policy, Vol.27 (2010), p. 628.

[10] Y.G. Cao, W.Zhou and J.wang: Comparative on regional cultivated land intensive use based on principal component analysis and analytic hierarchy process in Three Gorges Reservoir Area. Transactions of the CSAE, Vol.26 (2010) No.4, p.291. 